\title{
Attenuation of the heat shock response in HeLa cells is mediated by the release of bound heat shock transcription factor and is modulated by changes in growth and in heat shock temperatures
}

\author{
Klara Abravaya, Benette Phillips, and Richard I. Morimoto ${ }^{1}$ \\ Department of Biochemistry, Molecular Biology and Cell Biology, Northwestern University, Evanston, Illinois 60208 USA
}

\begin{abstract}
When HeLa S3 cells are subjected to a continuous $42^{\circ} \mathrm{C}$ heat shock, activation of heat shock transcription factor (HSF) and transcriptional activation of the heat shock genes $h s p 70, h s p 89 \alpha$, and $h s p 60$ is transient, peaking at 40-60 min of heat shock, and then attenuating. We have used in vivo genomic footprinting to demonstrate that attenuation of hsp 70 transcription is mediated by release of bound HSF from the heat shock element (HSE) of the hsp70 gene promoter. Release of bound HSF in vivo occurs at a higher rate than would be predicted from in vitro measurements of dissociation. Attenuation of HSF activation and heat shock gene transcription occurs only when mild heat shock temperatures are employed $\left(42^{\circ} \mathrm{C}\right)$; increasing the heat shock temperature by $1^{\circ} \mathrm{C}$ elicits a much higher level of activation, which does not attenuate during a 4-hr heat shock. Surprisingly, altering the temperature at which cells are grown prior to heat shock modulates the magnitude and temporal pattern of the response to a given heat shock temperature. This finding suggests that HSF does not sense temperature directly but, instead, may be responsive to the magnitude of the difference between growth and heat shock temperatures.
\end{abstract}

[Key Words: Heat shock; HeLa cells; HSF; HSE; transcriptional control]

Received July 8, 1991; revised version accepted August 8, 1991

The rapid induction of heat shock genes that occurs in all organisms upon exposure to elevated temperatures or other stresses has been studied intensively, both as a paradigm for gene regulation and because of its apparent importance to the survival of the organism under stressful conditions. Early studies of the heat shock response also revealed that expression of these genes decreases upon a return to pre-heat shock temperatures (recovery); moreover, attenuation of the response also occurs during prolonged exposure to elevated temperatures, especially if mild heat shock temperatures are employed (DiDomenico et al. 1982a,b; Mosser et al. 1988; Straus et al. 1990). Although this aspect of the response has received less attention than the activation component, several laboratories focusing on a diverse group of organisms have investigated the phenomenon of down-regulation, exploring the possibility that the products of the heat shock genes themselves autoregulate the response (DiDomenico et al. 1982b; Boorstein and Craig 1990; Stone and Craig 1990; Straus et al. 1990).

While an alteration in heat shock gene transcription in

${ }^{1}$ Corresponding author. response to upward and downward shifts in the ambient temperature appears to be the primary component of the heat shock response, there are fundamental differences between organisms in the mechanisms by which this transcriptional regulation is achieved. In Escherichia coli, transcriptional induction of heat shock genes is mediated by an alternative $\sigma$-factor, $\sigma^{32}$, that binds to the RNA core polymerase, thereby enabling the holoenzyme to recognize selectively the heat shock promoters (Grossman et al. 1984). The levels of this factor increase transiently during heat shock, as a result of increased synthesis and stability, allowing a transient burst of heat shock gene transcription (Grossman et al. 1987; Straus et al. 1987; Tilly et al. 1989). The synthesis and stability of $\sigma^{32}$ appear to be regulated negatively by $E$. coli heat shock proteins, resulting in a shutoff of the response despite maintenance of the cells at an elevated temperature (Tilly et al. 1989; Straus et al. 1990).

In all of the eukaryotes examined so far, transcriptional activation of heat shock genes relies on a specific heat shock transcription factor (HSF). This factor recognizes a consensus element (the heat shock element; HSE) in the promoter of these genes (Pelham 1982; Parker and Topol 1984; Sorger and Pelham 1987; C. Wu 
et al. 1987; Goldenberg et al. 1988). A regulatory feature that distinguishes Saccharomyces cerevisiae from higher eukaryotes is that in this species of yeast, HSF is bound to its recognition site prior to heat shock and apparently acquires enhanced ability to stimulate transcription upon heat shock (Sorger et al. 1987; Jakobsen and Pelham 1988). In higher eukaryotes, HSF is present in a non-DNA-binding form prior to heat shock and is activated by heat shock to bind DNA (Wu 1984; Kingston et al. 1987; Sorger et al. 1987; Mosser et al. 1988; Thomas and Elgin 1988; Abravaya et al. 1991).

The mechanisms underlying the shutoff of the heat shock response in eukaryotes are not well understood. By using yeast transformed with various HSE-containing promoter- $\beta$-gal fusion constructs, it has been demonstrated that the response to a prolonged heat shock can be either transient or sustained, depending on the nature of the promoter (Sorger 1990). These two types of responses have been shown to be a consequence of two distinct transcriptional activation domains in yeast HSF (Sorger 1990). Early studies in Drosophila suggested that the kinetics of recovery are affected by the level of heat shock proteins at the time of temperature downshift (DiDomenico et al. 1982b).

Our laboratory has used a different approach to study the attenuation of the heat shock response in human cells. We were interested in examining the changes in HSF-HSE interactions that might account for the decline in transcription of the endogenous $h s p 70$ gene during the attenuation phase of the heat shock response. To that end, we have used in vivo genomic footprinting to determine that attenuation of $h s p 70$ transcription is correlated closely with the release of HSF from HSE. Furthermore, we show that dissociation of HSF from the HSE of the $h s p 70$ promoter occurs at a rate faster than predicted from in vitro measurements of dissociation. We also demonstrate that attenuation of the heat shock response is regulated by both the temperature of heat shock and, more surprisingly, by the temperature at which the cells are grown prior to heat shock.

\section{Results}

HSF levels and transcription rates of three distinct heat shock genes decline with similar kinetics during the attenuation phase of the heat shock response

When HeLa cells are exposed to a prolonged $42^{\circ} \mathrm{C}$ heat shock, transcriptional induction of the $h s p 70$ gene and activation of HSF occur only during the initial phase of heat shock and then attenuate, despite the continued exposure of the cells to the elevated temperature (Mosser et al. 1988). To examine the attenuation phase of the heat shock response in more detail and to analyze HSFHSE interactions during this period, HeLa S3 cells were shifted from $37^{\circ} \mathrm{C}$ to $42^{\circ} \mathrm{C}$ and samples were withdrawn at selected times for transcription run-on assays, for gelshift analysis to measure levels of activated HSF, and for in vivo genomic footprinting. As shown in Figure 1A, there was a very rapid induction of $h s p 70$ transcription, with activation apparent even at $1 \mathrm{~min}$ following temperature upshift. After 20 min of heat shock, transcription of $h s p 70$ was elevated 50-fold, and transcription was maintained at this elevated level until the 60 -min time point. At this point, a gradual attenuation of transcription occurred, with transcription returning to its basal level after $4 \mathrm{hr}$ of continuous exposure to $42^{\circ} \mathrm{C}$. The transcription rates of two other heat shock genes, $h s p 89 \alpha$ and hsp60, were also monitored. Although neither gene was induced to the same extent as $h s p 70$, their patterns of transcriptional activation, maintenance, and attenuation were identical to that of $h s p 70$. The transcription of the non-heat-shock-responsive $\beta$-actin gene, which shows a transient increase in response to the pelleting of the cells prior to temperature shift (Fig. 1A, cf. lanes $\mathrm{l}^{\prime}$ and $\mathrm{C}$ ), returns to basal levels by 5 min of heat shock and diminishes gradually, consistent with previous observations of the behavior of this gene during heat shock (Abravaya et al. 1991).

In parallel with the transcriptional response of the heat shock genes, levels of activated HSF rise quickly to a peak, remain at the peak level during a $40-\mathrm{min}$ period, and attenuate gradually (Fig. 1B). A graphic comparison of activated HSF levels and the fold of transcriptional induction of $h s p 70$ reveals a virtual coincidence in the temporal patterns of these two parameters during the entire 4-hr heat shock time course (Fig. 1C). These results establish that the tight correlation between HSF levels and transcriptional induction of $h s p 70$, which is seen during the activation phase of the heat shock response (Abravaya et al. 1991), is maintained during the attenuation phase as well.

\section{Attenuation of hsp70 transcription is mediated by release of bound HSF from the HSE of the promoter}

The tight correlation between HSF levels and $h s p 70$ transcription, coupled with the previous demonstration that during a 1-hr heat shock, the intensity of HSF-HSE interactions in vivo was closely coupled to these two parameters (Abravaya et al. 1991), raised the question as to whether attenuation of transcription was mediated by a parallel attenuation of HSF-HSE interactions in vivo. This would imply that HSF bound to the HSE in vivo could be released readily so that occupancy of the HSE would be rapidly reflective of falling HSF levels. However, an alternative possibility, in which HSF remains bound to the HSE but loses its ability to stimulate transcription, must also be considered. This possibility is not necessarily excluded by the overall drop in activated HSF levels measured by gel-shift assay of samples taken during the attenuation phase, because HSF that is bound to functional HSE in vivo may represent a small fraction of the total activated HSF population. In the second scenario, a step in which bound HSF is inactivated would have to be postulated. To distinguish between these two possibilities, a genomic footprinting analysis of HSFHSE interactions during the attenuation phase was carried out.

The nature and organization of the elements that com- 
A

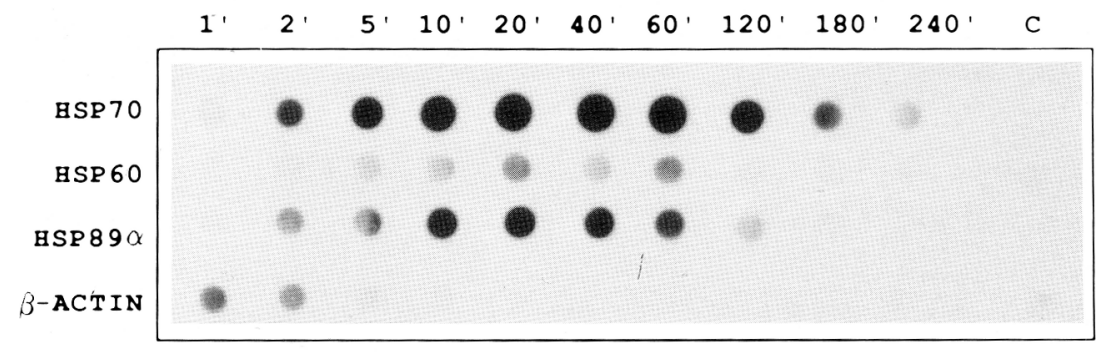

Figure 1. Anaiysis of transcription rates and HSF levels during a continous $42^{\circ} \mathrm{C}$ heat shock. (A) Transcription rates of $h s p 70$, hsp60, hsp $89 \alpha$ and $\beta$-actiil genes in HeLa S3 cells were measured by run-on assays prior to heat shock (lane $C$ ) and at the indicated times of heat shock. $(B)$ HSF levels were measured by gel-shift assays, by using whole-cell extracts prepared from HeLa S3 cells prior to heat shock $(C)$ and at the indicated times of heat shock. Complexes due to nonspecific (NS) DNA-binding proteins and HSF are shown by arrows. $(C)$ Graphic comparison of HSF levels and the transcription rate of the $h s p 70$ gene at the indicated times of heat shock. The filters from $A$ and the dried gel from $B$ were scanned and quantified with a Molecular Dynamics 400A Phosphorimager. Values were machine counts, plotted on an arbitrary scale.
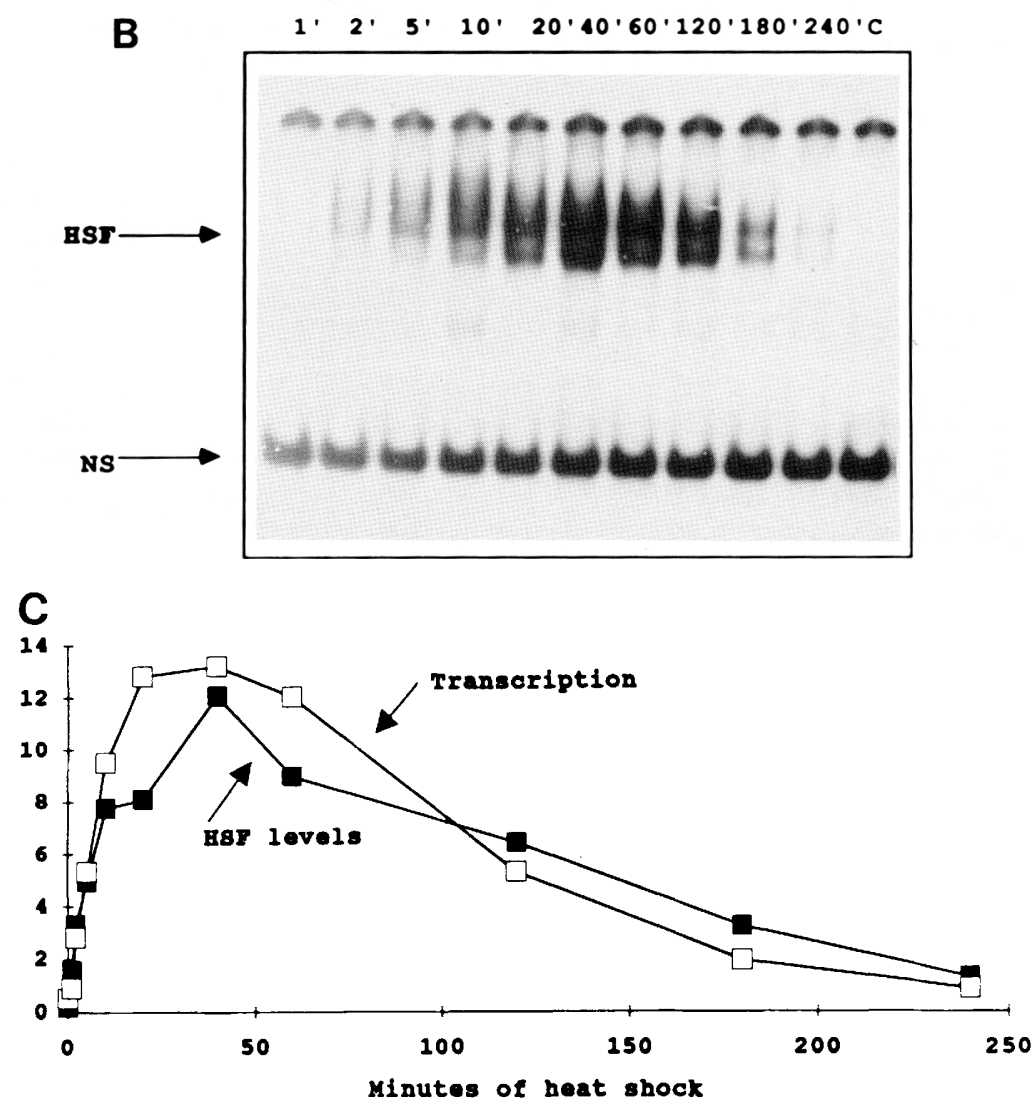

prise the human $h s p 70$ promoter are depicted in Figure 2. In addition to consensus-binding sites for the factors CTF, CBF, Spl, and TFIID, the promoter contains two HSEs (Morgan et al. 1987; B. Wu et al. 1987; Morgan 1989; Williams et al. 1989; Lum et al. 1990). The proximal HSE, which has been shown by transfection studies to be sufficient for heat shock induction (Wu et al. 1986; Williams and Morimoto 1990), consists of five contiguous alternating NGAAN units, three perfect (sites 1, 3, and 4 ) and two imperfect (sites 2 and 5) matches to the consensus sequence (Amin et al. 1988; Xiao and Lis 1988). Previous genomic footprinting analysis of this region during a $1-\mathrm{hr} 42^{\circ} \mathrm{C}$ heat shock revealed that the consensus $\mathrm{G}$ residue in each of these units (G-94, G-97, G-104, G-107, G-114) was protected from methylation during heat shock. There was also protection of adjacent G residues at two of these sites (G-96, G-105) and hypersensitivity to methylation in three guanine residues flanking the HSE (G-89, G-95, G-116) (Abravaya et al. 1991). This alteration in the methylation pattern can be seen in Figure 3A by comparing lanes $40^{\prime}$ (sample taken at $40 \mathrm{~min}$ of heat shock) and $\mathrm{C}$ (sample from control, i.e., non-heat-shocked cells) in both the coding and noncoding strand methylation patterns. It can also be seen that, consistent with the analysis published previously (Abravaya et al. 1991), no factor is bound to the HSE region prior to heat shock [cf. the patterns for naked DNA (lane N) and control DNA (lane C)]. During the attenuation phase of the heat shock response (lanes 120', $180^{\prime}, 240^{\prime}$ ), there is a gradual weakening of the protections and hypersensitivities seen in lane $40^{\prime}$, so that in samples taken after $4 \mathrm{hr}$ of continuous heat shock, the pattern resembles that of samples from non-heatshocked cells. The changes in the methylation pattern during the attenuation phase were quantitated by densitometric scanning of individual bands representing 


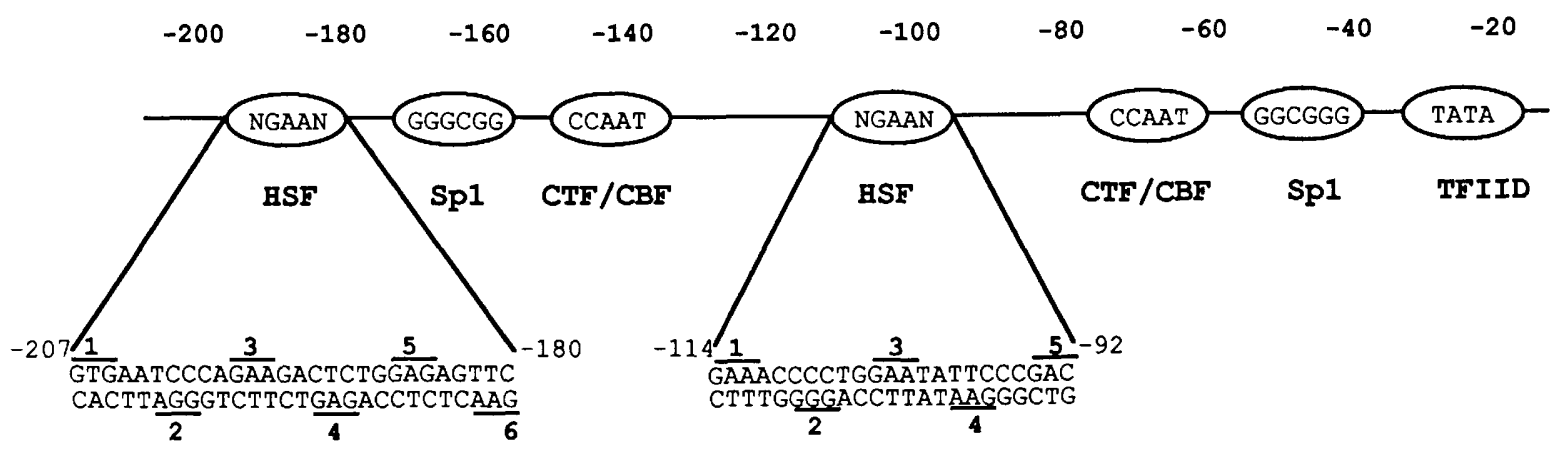

Figure 2. Schematic of the human $h s p 70$ promoter from -20 to -200 . Consensus sequences recognized by known transcription factors are circled, and the transcription factors that bind to these sites are indicated. The sequences of the distal (-190) and proximal $(-100)$ HSF-binding sites (HSEs) are shown, and the GAA units, comprising an array of repeated inverted units characteristic of HSEs, are underlined and numbered.

G-116, G-105, G-104, and G-94 on the coding strand and G-96, G-97, and G-107 on the noncoding strand. After 120 min of heat shock, there was a $50-70 \%$ decrease in the degree of protection from methylation of these $G$ residues as compared to the maximal protections in the 40 -min samples. This corresponds well to the $50 \%$ decrease from the maximal values in both levels of activated HSF and the rate of $h s p 70$ transcription that was seen at this same time point (Fig. $1 \mathrm{C}$ ). This result supports the suggestion that attenuation of $h s p 70$ transcription during a prolonged $42^{\circ} \mathrm{C}$ heat shock is mediated by the release of bound HSF from the HSE of the promoter and that occupancy of the HSE in vivo is not maintained when cellular levels of activated HSF decline.

Although the intensity of bands representing protected guanine residues in samples taken at $240 \mathrm{~min}$ of heat shock resembled that in non-heat-shocked cells, hypersensitivities at the two guanines flanking the HSE on its proximal side (G-89, G-95) were still apparent (Fig. 3A). The persistence of these hypersensitivities, which have been postulated to result from locally increased dimethylsulfate concentrations in hydrophobic pockets created by protein-DNA interactions (Becker and Schutz 1988) and which are very susceptible indicators of HSF binding, may reflect a very low level of residual HSF binding at this time point. Alternatively, hypersensitivities have been suggested to result from changes in chromatin structure related to HSF binding (Abravaya et al. 1991), and such changes may persist despite release of the bound factor.

The release of bound HSF from the hsp70 promoter in vivo occurs at a rate higher than that predicted from in vitro measurements of dissociation

Although both HSF levels and transcriptional activation attenuate during a sustained $42^{\circ} \mathrm{C}$ heat shock, this attenuation occurs more rapidly if cells are returned to $37^{\circ} \mathrm{C}$ after a $40-\mathrm{min}, 42^{\circ} \mathrm{C}$ heat shock (Figs. 4 and 5). Such a difference presumably reflects an ongoing, although constantly diminishing, signal for activation of HSF during the last $3 \mathrm{hr}$ of a prolonged heat shock, whereas a return of cells to $37^{\circ} \mathrm{C}$ would be expected to extinguish this signal more rapidly. During recovery at $37^{\circ} \mathrm{C}$, when activation of HSF is no longer occurring or has been reduced substantially, a measurement of the rate with which protections at the NGAAN sites diminish should allow an estimate of the in vivo rate of dissociation of the HSF-HSE complex.

Samples withdrawn at selected times during recovery at $37^{\circ} \mathrm{C}$ were analyzed by genomic footprinting (Fig. $6 \mathrm{~A}, \mathrm{~B})$. Within $15 \mathrm{~min}$ of the return of cells to $37^{\circ} \mathrm{C}$, protections at all five NGAAN sites were reduced markedly $(60-100 \%)$, and after $1 \mathrm{hr}$ at $37^{\circ} \mathrm{C}$, the methylation pattern (protections and hypersensitivites) was indistinguishable from that of control cells. Thus, in agreement with the analysis of cells maintained at $42^{\circ} \mathrm{C}$, the rapid decline of HSF levels is mirrored in a rapid release of bound HSF, and quantitation of the rate at which these protections diminish allows us to estimate the half-life of the HSF-HSE complex in vivo as $10-15 \mathrm{~min}$ (Fig. 7).

Because of the rapidity with which HSF is released during recovery, we wanted to determine whether dissociation of a HSF-HSE complex in vitro occurred equally as fast. The dissociation half-time of the HSF-HSE complex in vitro was determined previously in our laboratory (Mosser et al. 1988). This analysis was performed prior to our in vivo footprinting studies and employed an HSE oligomer that contained sites 3,4 , and 5 only (reflecting the view accepted of that time of the consensus HSE as a 14-bp sequence, CNNGAANNTTCNNG) and a dissociation temperature of $25^{\circ} \mathrm{C}$. To analyze the rate of dissociation in vitro so that a more appropriate comparison to the in vivo rate could be made, we utilized an HSE oligomer that included all five NGAAN sites, a wholecell extract from the same sample that was taken at 40 min of heat shock for use in genomic footprinting, and a dissociation temperature of $37^{\circ} \mathrm{C}$. The binding reaction was carried out as for a gel-shift assay, and a preformed, radiolabeled HSF-HSE complex was incubated with a 200 -fold excess of unlabeled oligomer. The decrease in the levels of radiolabeled complex with time was then determined. This determination yielded a value for the half-time of dissociation in vitro of $90 \mathrm{~min}$, substantially longer than the 10-15 min in vivo half-time (Fig. 7). The discrepancy between in vivo and in vitro rates of disso- 

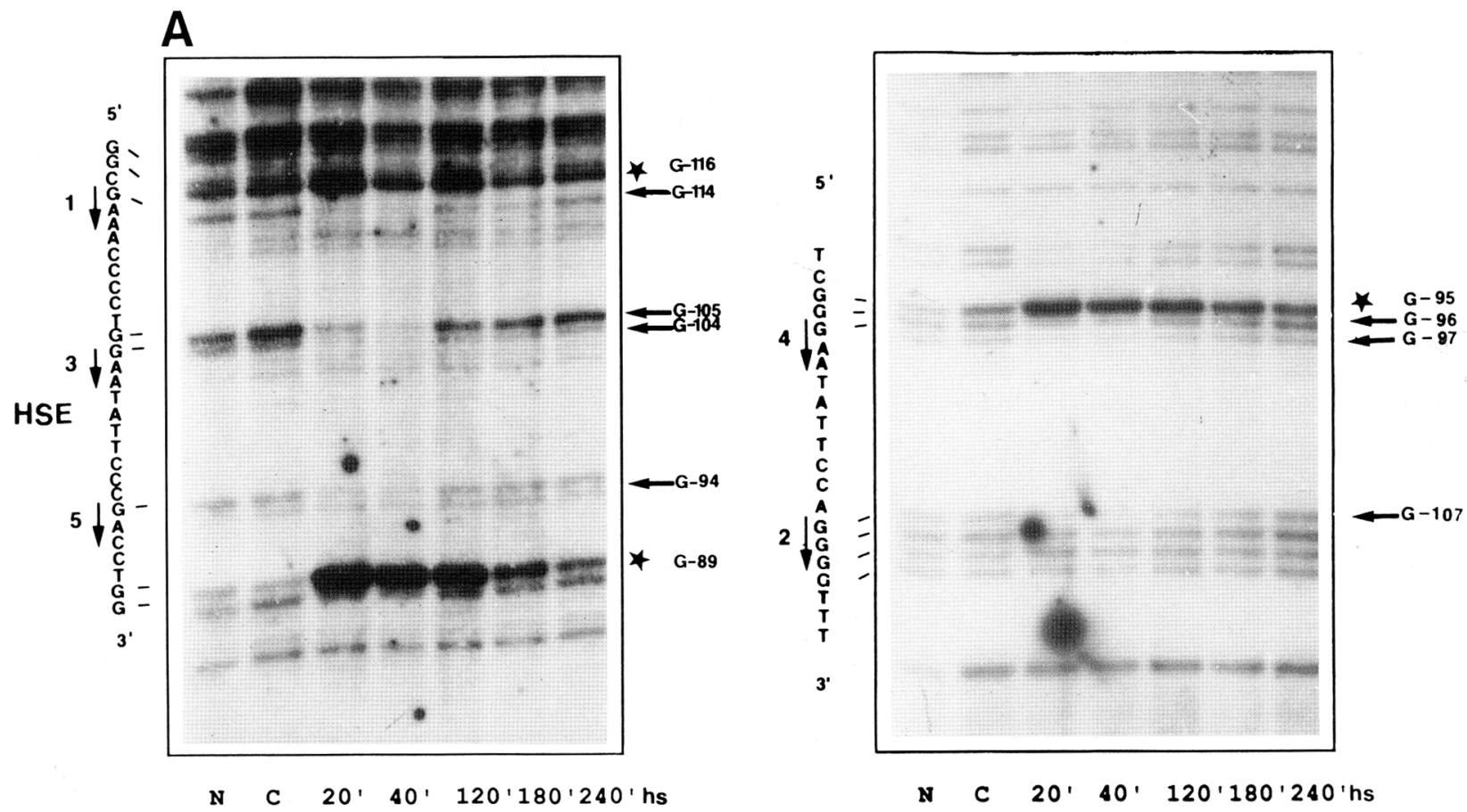

B

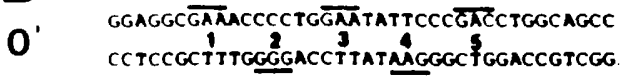

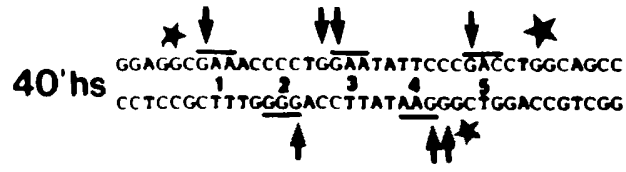

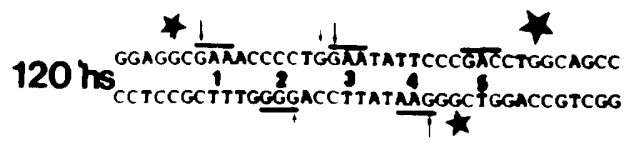

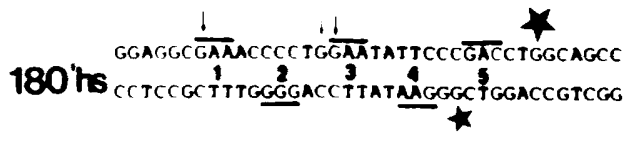

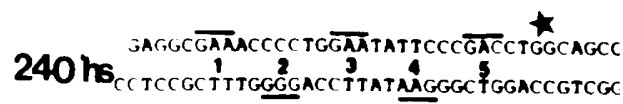

Figure 3. Genomic footprinting of the $h s p 70$ proximal HSE region during a continous $42^{\circ} \mathrm{C}$ heat shock. (A) Methylation patterns in genomic DNA isolated at the indicated times during heat shock. [Lane $N$ (naked)] Deproteinized DNA, methylated in vitro; [lane $C$ (control) DNA] was isolated from non-heat-shocked cells. The HSE sequence, with the GAA sites numbered as in Fig. 2., is shown adjacent to the methylation patterns for the coding (Ieft) and noncoding (right) strand. Arrows denote guanine residues protected from methylation; stars denote guanines hypersensitive to methylation. Band intensities were determined by densitometric scanning, and guanines were judged hypersensitive or protected from methylation on the basis of normalization to neighboring bands that did not show any altered reactivity. $(B)$ Summary of quantitations of DMS reactivity patterns of the proximal HSE region at the indicated times of heat shock. The larger arrows and stars denote two- to threefold differences in reactivities of guanines when compared with the corresponding guanine in DNA from non-heat-shocked cells; the smaller arrows and stars reflect differences less than twofold. ciation suggests that in vivo, release of bound HSF may be a facilitated event.

The magnitude and pattern of the heat shock response are modulated by temperature of heat shock and by temperature at which cells are grown prior to heat shock

The experiments presented so far describe and analyze the attenuation phase of the heat shock response, which is seen in cells heat-shocked at $42^{\circ} \mathrm{C}$. We wanted to determine whether the response attenuated regardless of the severity of the heat shock. HeLa cells were therefore subjected to a continuous heat shock at $41^{\circ} \mathrm{C}, 42^{\circ} \mathrm{C}$, or $43^{\circ} \mathrm{C}$. At selected times, samples were withdrawn for gel-shift analysis and for transcription run-on assays. In cells that were shifted to $43^{\circ} \mathrm{C}$, levels of activated HSF were considerably higher than in cells shifted to $42^{\circ} \mathrm{C}$, 
A

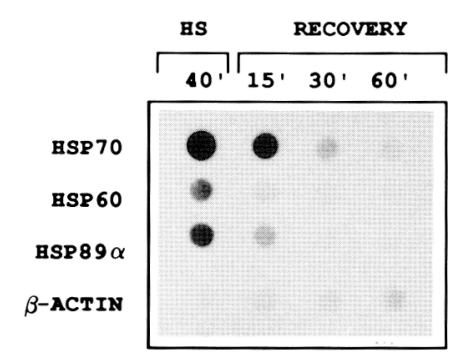

B

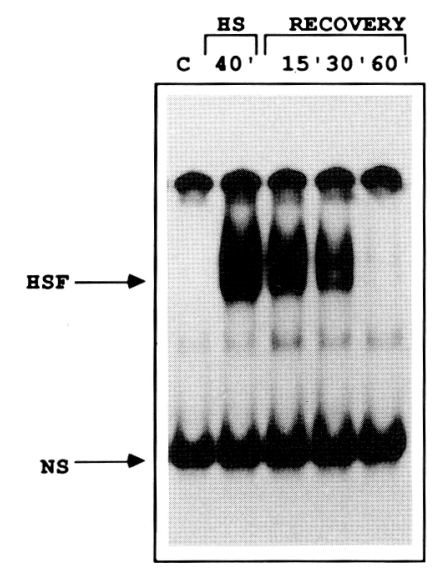

Figure. 4. Analysis of transcription rates and HSF levels during recovery at $37^{\circ} \mathrm{C}$. As part of the same experiment shown in Fig. 1, HeLa S3 cells, which had been heat-shocked for $40 \mathrm{~min}$ (HS), were allowed to recover at $37^{\circ} \mathrm{C}$ (Recovery). (A) Transcription rates of $h s p 70, h s p 60, h s p 89 \alpha$, and $\beta$-actin genes were measured by run-on assays after 40 min of heat shock and at the indicated times during recovery. $(B)$ Levels of activated HSF were measured at the indicated times by gel-shift assays as described in Fig. 1. Complexes due to nonspecific (NS) DNA-binding proteins and heat shock factor (HSF) are shown by arrows.

and these high levels were maintained during the entire 4-hr heat shock (Fig. 8A). Cells maintained at $41^{\circ} \mathrm{C}$ for 4 hr showed barely measurable levels of activated HSF (Fig. 8A). Nuclei run-on assays of hsp70 transcription yielded results that were consistent with HSF levels (data not shown). These data indicate that in human cells, a transient response to heat shock is evoked only at mild heat shock temperatures; a $1{ }^{\circ} \mathrm{C}$ increase in the heat shock temperature elicits a much stronger response that does not attenuate during a 4-hr period of exposure.

Surprisingly, it is not only the absolute heat shock temperature that dictates the extent of HSF activation and whether an attenuation phase is observed. We found that the magnitude and temporal pattern of the response to a specific heat shock temperature could be modulated by altering the temperature at which the cells were grown prior to heat shock (Fig. 8B). When cells were grown at $35^{\circ} \mathrm{C}$ for several days prior to heat shock, a continuous $42^{\circ} \mathrm{C}$ heat shock elicited high levels of activated $\mathrm{HSF}$, which were maintained during the entire 4-hr heat shock period. A transient response, typically evoked by a $42^{\circ} \mathrm{C}$ heat shock of cells grown at $37^{\circ} \mathrm{C}$, was observed when cells grown at $35^{\circ} \mathrm{C}$ were shifted to $41^{\circ} \mathrm{C}$ /a temperature that elicited barely detectable levels of activated $\mathrm{HSF}$ in cells grown at $37^{\circ} \mathrm{C}$ ). Transcription run-on assays yielded results compatible with those of the gelshift assays (data not shown). These data indicate that the absolute temperature of heat shock is not the sole determinant of the magnitude and duration of HSF activation. It appears instead that the response may depend on the magnitude of the difference between the growth temperature and the temperature of heat shock.

\section{Discussion}

Our results reveal several noteworthy features of the attenuation phase of the heat shock response in HeLa S3 cells. First, the decline in transcription rates of three distinct heat shock genes follows similar kinetics. Second, in the case of the $h s p 70$ gene, the decline in transcription is an apparent consequence of the release of bound HSF from the HSE. This release of bound HSF occurs at a higher rate in vivo than would be predicted from in vitro measurements of dissociation rates. Third, the heat shock response attenuates only when temperatures that elicit submaximal enhancement of heat shock gene transcription are employed. Finally, the heat shock temperature at which cells exhibit a multiphasic response is not an absolute value but can be modulated by the growth temperature.

The initial response of $\mathrm{HeLa} \mathrm{S} 3$ cells to a $42^{\circ} \mathrm{C}$ heat shock is a rapid increase in the transcription rate of the hsp70 gene (as well as two other heat shock genes), accompanied by a parallel elevation in the levels of activated HSF. However, despite continued exposure to elevated temperature, after $\sim 40$ min of heat shock a switch is flipped, reversing the process of HSF activation, and the transcription of $h s p 70$ declines, eventually returning to basal levels. Our in vivo footprinting analysis of HSFHSE interactions demonstrates that transcriptional attenuation during continous heat shock is mediated by a release of bound HSF from the HSE rather than by events that inactivate the bound factor.

We also found that release of bound HSF from the hsp70 promoter in vivo occurs much more rapidly than does release of activated HSF from an oligomer whose sequence matches that of the proximal HSE. This suggests that release in vivo is facilitated, either by modification of bound HSF or by the participation of additional factors in the dissociation process. It is also possible that release of $\mathrm{HSF}$ from its endogenous binding site, which is embedded in chromatin and flanked by additional DNA sequences and associated transcription factors, occurs more readily than release of the factor from an isolated fragment of DNA in vitro. Differences in the nuclear and in vitro environments may also modulate the kinetics of release.

An attractive hypothesis is that heat shock proteins themselves may contribute to the deactivation of HSF and/or the release of bound HSF, thereby providing an autoregulatory loop. However, despite evidence for the 
A

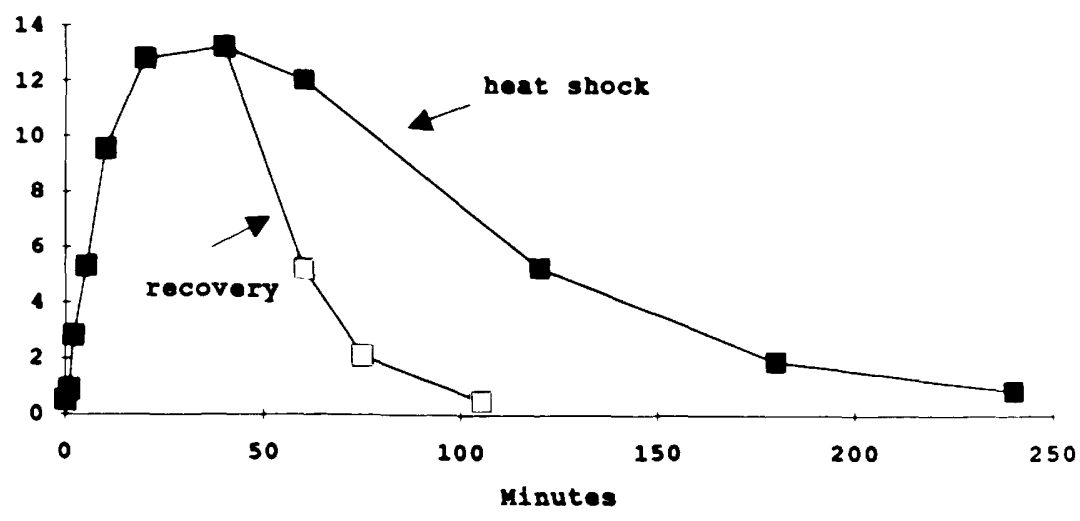

B

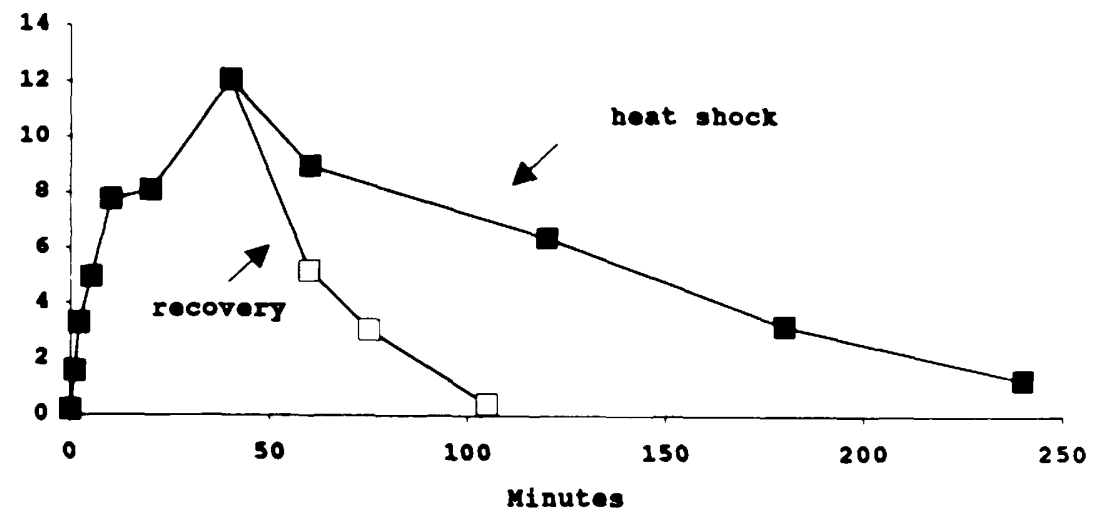

Figure 5. Comparison of attenuation of hsp70 transcription and levels of activated HSF during continous heat shock and during recovery at $37^{\circ} \mathrm{C}$. (D) Samples during continous heat shock at $42^{\circ} \mathrm{C}$; $(\square)$ samples during recovery at $37^{\circ} \mathrm{C}$. $(A)$ The regions of filters hybridized to labeled $h s p 70$ transcripts from transcription assays shown in Figs. $1 \mathrm{~A}$ and $3 \mathrm{~A}$ were scanned, quantified, and plotted on an arbitrary scale. $(B)$ Regions of the gels containing complexes as a result of HSF from gelshift assays shown in Figs. $1 \mathrm{~B}$ and $3 \mathrm{~B}$ were scanned, quantified, and plotted on an arbitrary scale. regulation of $\sigma-32$ synthesis and stability by $E$. coli heat shock proteins (Tilly 1989; Straus et al. 1990), as yet there has been no demonstration that HSF activity is regulated by heat shock proteins in eukaryotes. Two recent reports from the laboratory of E. Craig have addressed the question of autoregulation in $S$. cerevisiae (Boorstein and Craig 1990; Stone and Craig 1990). In one case, the autoregulation has been shown to be mediated through an HSE (Boorstein and Craig 1990).

The deviation of natural HSE sequences from the consensus, as exemplified by the proximal HSE of the hsp70 promoter, may represent an essential component of the mechanism that permits the rapid release of bound HSF from the promoter and thus the rapid down-regulation of heat shock gene transcription. Xiao et al. (1991) have demonstrated recently that dissociation of purified Drosophila HSF from an array of five perfect NGAANbinding units occurs extremely slowly. We have also observed that in a HeLa S3 whole-cell extract, dissociation of HSF from an oligomer comprising four perfect NGAAN repeats occurs much more slowly than from an oligomer representing the proximal HSE of the $h s p 70$ promoter, in which only three of five units are perfect matches to the consensus.

In addition to the HSE centered at -100 , the hsp 70 promoter contains a distal HSE located at -200 . This HSE consists of six NGAAN repeats, only two of which are perfect matches to the consensus (Fig. 2). During the attenuation phase, HSF is released from the distal HSE with kinetics identical to that of release from the proximal HSE (data not shown). The HSE of the $h s p 89 \alpha$ gene (whose transcription attenuates with the same kinetics as the $h s p 70$ gene) consists of an array of five NGAAN units, only three of which are perfect matches to the consensus, as is the case for the proximal HSE of the $h s p 70$ promoter (Hickey et al. 1989). Assuming that the attenuation of $h s p 89 \alpha$ transcription reflects the release of bound HSF from the $h s p 89 \alpha$ HSE, dissociation of HSF from three distinct HSEs occurs with very similar kinetics. Although one view of the situation in vivo is that HSEs with varying affinities for HSF are competing for the factor (Xiao et al. 1991), it is also possible that within any one species, HSEs in the various heat shock promoters have evolved to possess similar affinities for HSF, allowing a coordinate pattern of response to heat shock, at least at the transcriptional level. Although the synthesis of various heat shock proteins did not occur in a coordinate fashion in Drosophila (Lindquist 1980), these results may reflect variations in post-transcriptional regulation between heat shock genes rather than noncoordinate transcription or may signify a basic difference between the heat shock response in Drosophila and mammalian species.

An examination of the response of $\mathrm{HeLa} \mathrm{S} 3$ cells to 


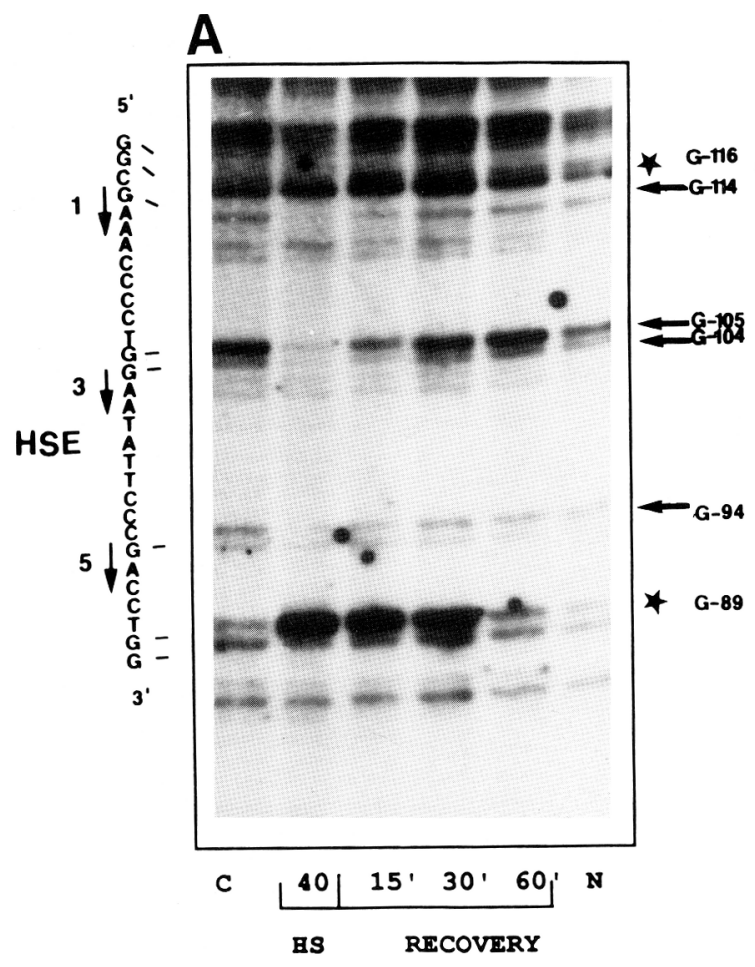

Figure 6. Genomic footprinting of the $h s p 70$ proximal HSE region during recovery at $37^{\circ} \mathrm{C}$. As part of the same experiment shown in Fig. 3A, HeLa S3 cells that had been heat shocked for $40 \mathrm{~min}(\mathrm{HS})$ were allowed to recover at $37^{\circ} \mathrm{C}$ (Recovery). (A) Methylation patterns in genomic DNA isolated from cells at 40 min of heat shock and at the indicated times during recovery. [Lane $N$ ] (naked)] Deproteinized DNA, methylated in vitro; [lane $C$ (control)] DNA was isolated from non-heat-shocked cells. The HSE sequence, where the GAA sites are numbered as in Fig. 2., is shown adjacent to the methylation patterns for the coding (left) and noncoding (right) strand. Arrows denote guanine residues protected from methylation; stars denote guanines hypersensitive to methylation. Band intensities were determined by densitometric scanning, and guanines were judged hypersensitive or protected from methylation on the basis of normalization to neighboring bands that did not show any altered reactivity. $(B)$ Summary of quantitations of DMS reactivity patterns of the proximal HSE region at $40 \mathrm{~min}$ of heat shock and at the indicated times of recovery. The larger arrows and stars denote two- to threefold differences in reactivities of guanines when compared with the corresponding guanine in DNA from non-heat-shocked cells; the smaller arrows and stars reflect less than twofold differences.

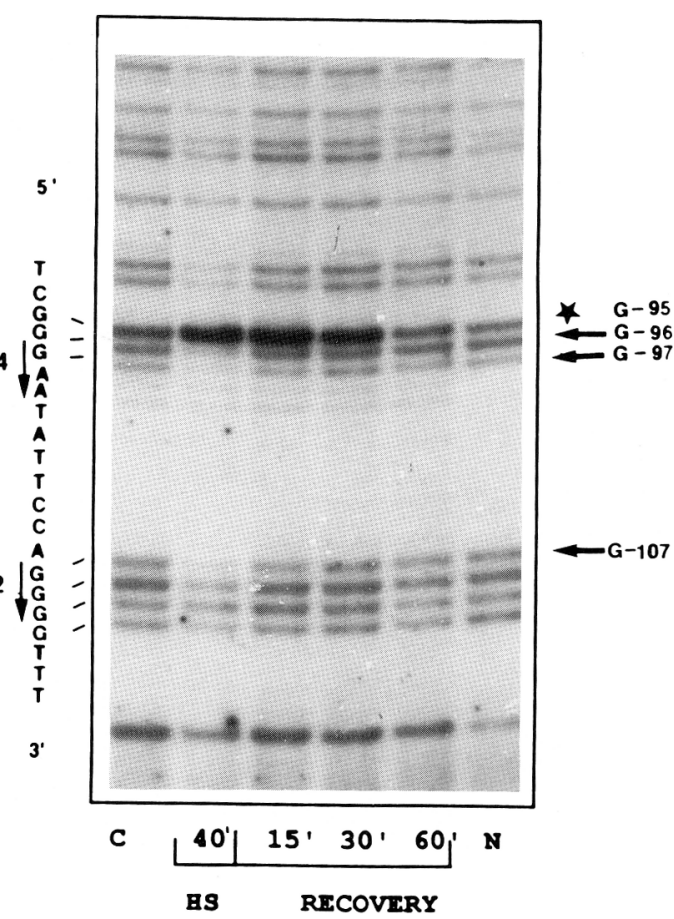

B

B. GaGGCGAMACCCCTGGMATATTCCCERCCTGGCAGCC
$0^{\prime}$ CCTCCGCTTTGGGGACCTTATAAGGGCFGACCGTCGC

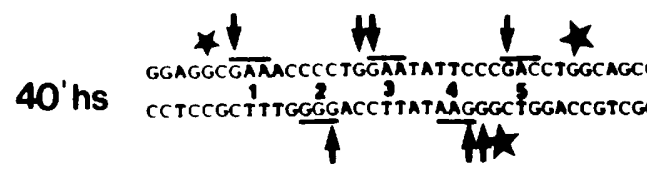

15 'R

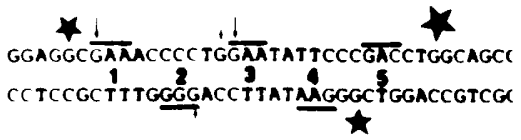

30'R

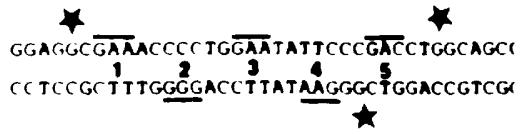

60'R

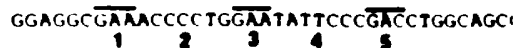
CCTCCGC ITTGGGGACCTIATAAGGGCFGACCGTCG continuous heat shock at different temperatures revealed that increasing the severity of the heat shock virtually abolished the attenuation phase, at least during the 4-hr period monitored. Thus, in HeLa S3 cells, one can alter the pattern of response of heat shock genes from transient to sustained by changing the temperature of heat shock. One interpretation of this finding rests on the assumption that heat-induced protein damage provides the signal for HSF activation. During a mild heat shock, heat shock protein-mediated repair of protein damage and/or prevention of further damage would diminish this signal, whereas during a more severe heat shock, the capacity of the cell to counter the damage would be exceeded and the signal for HSF activation 
Figure 7. Comparison of in vivo and in vitro rates of dissociation of HSF from the HSE. The decrease in protection from methylation of indicated guanines during recovery from a $42^{\circ} \mathrm{C}$, 40 -min heat shock is denoted by the arrow labeled in vivo. (口) G-114 (1); (口) G-107 (2); ( )

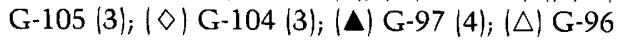
(4); ( $\triangle$ ) G-94 (5). The number in parenthesis denotes the number of the NGAAN site to which each guanine corresponds. Densitometric scanning of the autoradiogram shown in Fig. 6A was used to determine the intensities of bands corresponding to these guanines, normalizing to neighboring bands representing guanines whose reactivity to methylation is not affected by heat shock. The intensities of these bands in the 40min heat-shocked sample were arbitrarily taken to represent maximal binding, and the intensities of these bands in the non-heat-shocked

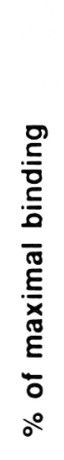
sample were taken to represent the absence of HSF binding. The rate of dissociation of the HSF-HSE complex in vitro, denoted by the arrow labeled in vitro, is also plotted. The whole-cell extract from the 40-min heat-shocked sample taken in the experiment shown in Fig. 6A was incubated with a ${ }^{32} \mathrm{P}$-labeled oligomer, whose sequence matched that of HSE of the hsp 70 promoter. After a 20 -min incubation at $25^{\circ} \mathrm{C}$, a 200 -fold excess of unlabeled oligomer was added. (Insert) The autoradiogram indicates the amount of HSF-HSE complex prior to the addition of competitor $|-|$ and at the indicated times after the addition of competitor. The dried gel was scanned and quantitated by using a Molecular Dynamics 400A Phosphorimager, and the results were plotted, with the amount of HSF-HSE complex prior to the addition of competitor being taken to represent $100 \%$ binding.

would persist. The recent cloning of two distinct human HSF genes (Rabindran et al. 1991; Schuetz et al. 1991) raises another issue that must be considered in interpreting our data. The relative contribution of each of these factors to transcriptional stimulation during heat shock has not been determined, and it is possible that their relative contributions vary according to the severity of heat shock. In the case of yeast HSF, which is present as a single gene, separate domains that mediate a transient or a sustained response have been described (Sorger 1990). It is possible that in human cells, transient and sustained activation are mediated by two distinct proteins.

The effect of varying the growth temperature on the synthesis of $h s p 70$ protein over a range of heat shock temperatures was investigated in Drosophila $>10$ years ago (Lindquist 1980). In contrast with our findings, it was reported that varying the growth temperatures of Drosophila cells between $19^{\circ} \mathrm{C}$ and $26^{\circ} \mathrm{C}$ had little effect on the pattern of heat shock response. The present study differs from this earlier work in several important respects, any or all of which could be responsible for the divergent results. Our study examines effects of changes in growth temperature utilizing cells of a homeothermic species, whereas the former study employed cells from a poikilothermic organism. We monitored the activation/deactivation of HSF during the heat shock response, whereas in the Drosophila study hsp70 synthesis was assayed. Drosophila cells express hsp 70 during heat shock only, whereas in HeLa S3 cells $h s p 70$ is constitutively expressed. We observe a dramatic alteration in the response to a given heat shock temperature resulting from a $2^{\circ} \mathrm{C}$ change in the growth temperature. This suggests that HSF is not sensing temperature directly; rather, it is the magnitude of the difference between growth and heat shock temperatures that influences the extent and temporal pattern of HSF activation and deactivation. Thus, activation and deactivation are not "hard-wired" responses.

\section{Materials and methods \\ Cell culture and heat shock conditions}

HeLa S3 cells were grown in Joklik's medium supplemented with $5 \%$ calf serum. In experiments where effects of growth temperature on the heat shock response were examined, cells were grown in temperature-controlled $\left( \pm 0.1^{\circ} \mathrm{C}\right)$ water baths for $96 \mathrm{hr}$ prior to heat shock. Cells were concentrated by centrifugation $(600 \mathrm{~g}, 5 \mathrm{~min})$ and resuspended at a density of $8 \times 10^{5}$ cells $/ \mathrm{ml}$ in spent medium that had been prewarmed to the temperature of heat shock. After $40 \mathrm{~min}$ of heat shock, an aliquot of cells was returned to $37^{\circ} \mathrm{C}$ to recover, whereas the remaining cells were maintained at the heat shock temperature. At selected times, $4 \times 10^{6}$ cells were pelleted and frozen at $-80^{\circ} \mathrm{C}$ for preparation of whole-cell extracts, nuclei from $1.2 \times 10^{7}$ cells were isolated and frozen for use in transcription run-on assays, and $2 \times 10^{7}$ cells were used for genomic footprinting.

\section{Measurement of transcription rates}

Isolation of nuclei and transcription run-on analysis were as described previously (Mosser et al. 1988). The following plasmids were immobilized on filters and hybridized to labeled transcripts: pH 2.3 (human hsp 70; Wu et al. 1985); pUC801, human hsp89a, kindly provided by L. Weber (Hickey et al. 1989); pUCHS601, human hsp60, kindly provided by L. Weber (Hickey et al. 1986); and pHF $\beta$ A-1 (human $\beta$-actin; Gunning et al. 1983). 
A

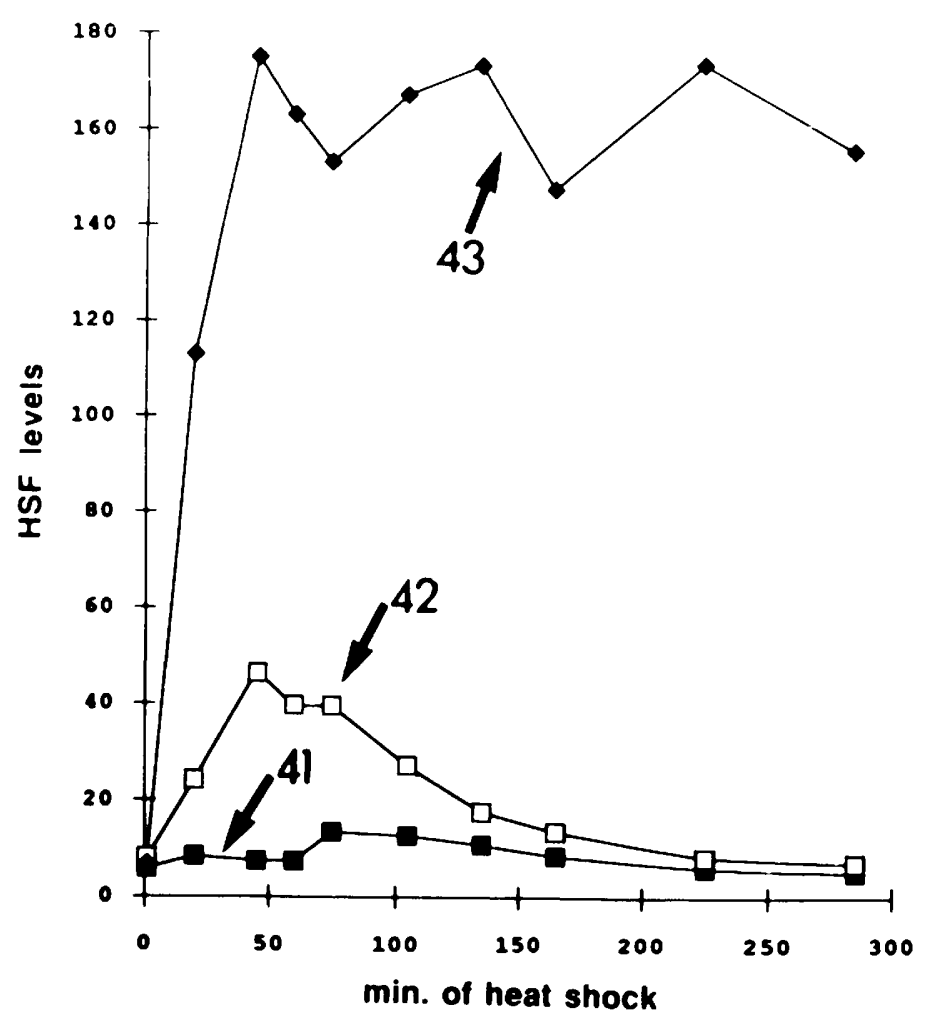

B

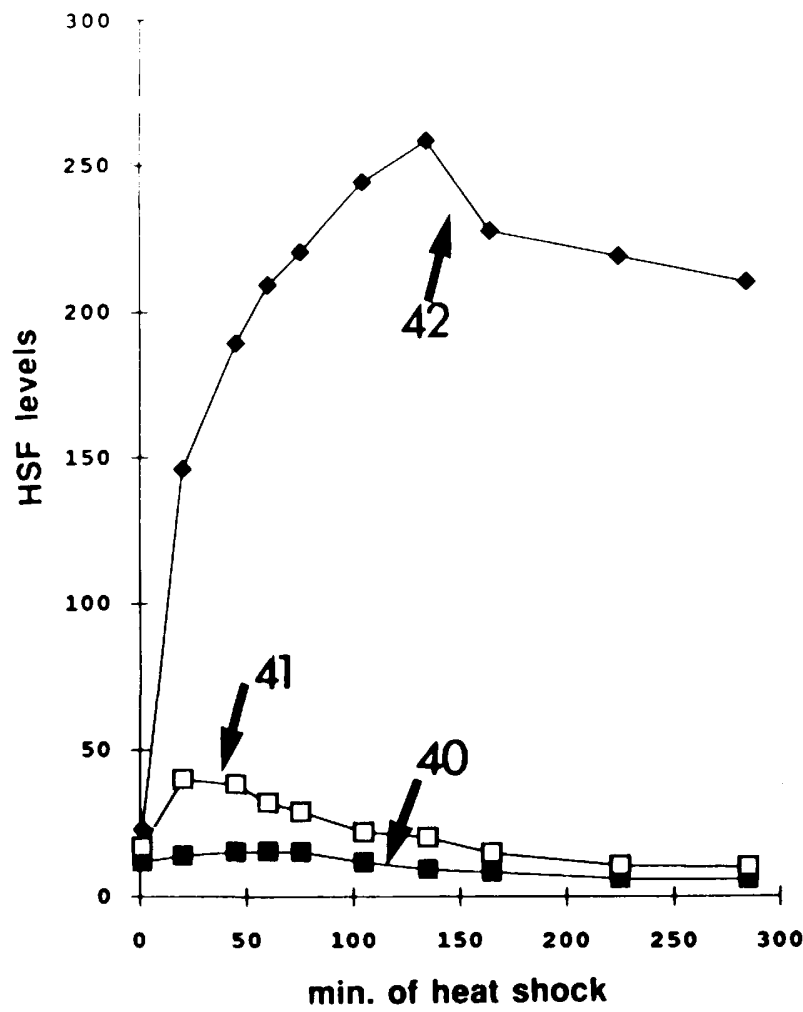

Figure 8. Effect of heat shock and growth temperatures on the activation and deactivation of HSF. Levels of activated HSF at the indicated times of heat shock were measured by gel-shift assay. The dried gels were scanned and quantified by using a Molecular Dynamics 400A Phosphorimager. Values are machine counts, plotted on an arbitrary scale. (A) Cells were grown for 4 days at $37^{\circ} \mathrm{C}$ prior to heat shock at $41^{\circ} \mathrm{C}, 42^{\circ} \mathrm{C}$ and $43^{\circ} \mathrm{C} .(B)$ Cells were grown for 4 days at $35^{\circ} \mathrm{C}$ prior to heat shock at $40^{\circ} \mathrm{C}, 41^{\circ} \mathrm{C}$, and $42^{\circ} \mathrm{C}$.

\section{Gel mobility-shift assay}

Conditions for the gel-shift assay, a description of the ${ }^{32} \mathrm{p}-\mathrm{la}$ beled HSE oligonucleotide, and preparation of whole-cell extracts were as published previously (Mosser et al. 1988).

\section{Genomic footprinting analyses}

Genomic footprinting of samples taken during heat shock and recovery was performed as described previously (Abravaya et al. 1991) by using a ligation-mediated polymerase chain reaction (Mueller and Wold 1989). Duplicate samples were analyzed at each time point. Primers used for footprinting of the coding and noncoding strands of the proximal HSE region of the $h s p 70$ promoter were described previously (Abravaya et al. 1991).

\section{Measurement of in vitro dissociation rate of HSF from HSE}

To measure the stability of the HSE-HSF complex, binding reactions were incubated at $25^{\circ} \mathrm{C}$ for $20 \mathrm{~min}$ before the addition of a 200-fold molar excess of unlabeled HSE oligonucleotide. This mixture was then incubated at $37^{\circ} \mathrm{C}$, and the amount of complex remaining at selected times was determined by gel electrophoresis. The HSE oligonucleotide used in this assay comprises five NGAAN sites and contains the sequences from -120 to -96 of the human hsp 70 promoter.

\section{Acknowledgments}

We thank members of the Morimoto laboratory and B. Wu for careful reading of the manuscript, and Sue Fox for her assistance in the preparation of the figures. This work was supported by grants from the National Institutes of Health (NIH) and March of Dimes, and an American Cancer Society (ACS) Faculty Research Award to R.I.M.; NIH postdoctoral fellowships to K.A. and B.P.; and ACS postdoctoral fellowship to K.A.

The publication costs of this article were defrayed in part by payment of page charges. This article must therefore be hereby marked "advertisement" in accordance with 18 USC section 1734 solely to indicate this fact.

\section{References}

Abravaya, K., B. Phillips, and R.I. Morimoto. 1991. Heat shockinduced interactions of heat shock transcription factor and the human hsp70 promoter examined by in vivo footprinting. Mol. Cell. Biol. 11: 586-592.

Amin, J., J. Ananthan, and R. Voellmy, 1988. Key features of heat shock regulatory elements. Mol. Cell. Biol. 8: 37613769.

Becker, P.B. and G. Schutz. 1988. Genomic footprinting. In Genetic engineering, principles and methods, (ed. J.K. Setlow) pp. 1-19. Plenum Press, New York.

Boorstein, W.R. and E.A. Craig. 1990. Transcriptional regulation of $s s a 3$, an hsp70 gene from Saccharomyces cerevisiae. Mol. Cell. Biol. 10: 3262-3267.

DiDomenico, B.J., G.E. Bugaisky, and S. Lindquist. 1982a. Heat shock and recovery are mediated by different translational mechanisms. Proc. Nat1. Acad. Sci. 79: 6181-6185. 
1982b. The heat shock response is self-regulated at both the transcriptional and posttranscriptional levels. Cell 31: 593-603.

Goldenberg, C.J., Y. Luo, M. Fenna, R. Baler, R. Weinmann, and R. Voellmy. 1988. Purified human factor activates heat shock promoter in a HeLa cell-free transcription system. J. Biol. Chem. 263: 19734-19739.

Grossman, A.D., J.W. Erikson, and C.A. Gross. 1984. The htpR gene product of E. coli is a sigma factor for heat shock promoters. Cell 38: 383-390.

Grossman, A.D., D.B. Straus, W.A. Walter, and C.A. Gross. 1987. Sigma 32 synthesis can regulate the synthesis of heat shock proteins in Escherichia coli. Genes \& Dev. 1: 179184.

Gunning, P., P. Ponte, H. Okayama, J. Engel, H. Blau, and L. Kedes. 1983. Isolation and characterization of full-length c-DNA clones for human $\alpha-, \beta$ - and $\gamma$-actin mRNAs: Skeletal but not cytoplasmic actins have an amino-terminal cysteine that is subsequently removed. Mol. Cell. Biol. 3: 787-795.

Hickey, E., S.E. Brandon, S. Sadis, G. Smale, and L.A. Weber. 1986. Molecular cloning of sequences encoding the human heat shock proteins and their expression during hyperthermia. Gene 43: 147-154.

Hickey, E., S.E. Brandon, G. Smale, D. Lloyd, and L.A. Weber. 1989. Sequence and regulation of a gene encoding a human 89-kilodalton heat shock protein. Mol. Cell. Biol. 9: 26152626.

Jakobsen, B.K. and H.R.B. Pelham. 1988. Constitutive binding of yeast heat shock factor to DNA in vivo. Mol. Cell. Biol. 8: $5040-5042$.

Kingston, R.E., T.J. Schuetz, and Z. Larin. 1987. $\mathrm{F}^{-}$at inducible human factor that binds to a human hsp70 promoter. Mol. Cell. Biol. 7: 1530-1534.

Lindquist, S. 1980. Varying patterns of protein synthesis in Drosophila during heat shock: Implications for regulation. Dev. Biol. 77: 463-479.

Lum, L.S.Y., L.A. Sultzman, R.J. Kaufman, D.I.H. Linzer, and B.J. Wu. 1990. A cloned human CCAAT-box-binding factor stimulates transcription from the human hsp70 promoter. Mol. Cell. Biol. 10: 6709-6717.

Morgan, W.D. 1989. Transcription factor Spl binds to and activates a human hsp70 gene promoter. Mol. Cell. Biol. 9: 4099-4104.

Morgan, W.D., G.T. Williams, R.I. Morimoto, J. Greene, R.E. Kingston, and R. Tijan. 1987. Two transcriptional activators, CCAAT-box binding transcription factor and heat shock transcription factor, interact with a human HSP70 gene promoter. Mol. Cell. Biol. 7: 1129-1138.

Mosser, D.D., N.G. Theodorakis, and R.I. Morimoto. 1988. Coordinate changes in heat shock element binding activity and hsp70 gene transcription rates in human cells. Mol. Cell. Biol. 8: 4736-4744.

Mueller, P.R. and B. Wold. 1989. In vivo footprinting of a muscle specific enhancer by ligation mediated PCR. Science 246: 780-785.

Parker, C.S. and J. Topol. 1984. A Drosophila RNA polymerase II transcription factor specific for the heat shock gene binds to the regulatory site of an hsp70 gene. Cell 37: 273-283.

Pelham, H.R.B. 1982. A regulatory upstream promoter element in the Drosophila hsp70 heat shock gene. Cell 30: 517-528.

Rabindran, S.K., G. Giorgi, J. Clos, and C. Wu. 1991. Molecular cloning and expression of a human heat shock factor, HSF1. Proc. Natl. Acad. Sci. 88: 6906-6910.

Schuetz, T.J., G.J. Gallo, L. Sheldon, P. Tempst, and R.E. Kingston. 1991. Isolation of a cDNA for HSF2: Evidence for two heat shock factor genes in humans. Proc. Natl. Acad. Sci.
88: 6910-6915.

Sorger, P.K. 1990. Yeast heat shock factor contains separable transient and sustained response transcriptional activators. Cell 62: 793-805.

Sorger, P.K. and H.R.B. Pelham. 1987. Purification and characterization of a heat shock element binding protein from yeast. $E M B O$ I. 6: 3035-3041.

Sorger, P.K., M.J. Lewis, and M.H.B. Pelham. 1987. Heat shock factor is regulated differently in yeast and HeLa cells. Nature 329: 81-84.

Stone, D.E. and E.A. Craig. 1990. Self regulation of 70-kilodalton heat shock proteins in Saccharomyces cerevisiae. Mol. Cell. Biol. 10: 1622-1632.

Straus, D.B., W.A. Walter, and C.A. Gross. 1987. The heat shock response of $\mathrm{E}$. coli is regulated by changes in the concentration of sigma 32. Nature 329: 348-351.

. 1990. DnaK, DnaJ, and GrpE heat shock proteins negatively regulate heat shock gene expression by controlling the synthesis and stability of $\sigma^{32}$. Genes \& Dev. 4: 2202-2209.

Thomas, G.H. and S.C.R. Elgin. 1988. Protein/DNA architecture of the DNAse I hypersensitive region of the Drosophila hsp26 promoter. EMBO I. 7: 2191-2201.

Tilly, K., J. Spence, and C. Georgopoulos. 1989. Modulation of stability of the Escherichia coli heat shock regulatory factor sigma 32. J. Bacteriol. 171: 1585-1589.

Williams, G.T. and R.I. Morimoto. 1990. Maximal stress induced transcription from the human hsp70 promoter requires interactions with the basal promoter elements independent of rotational alignment. Mol. Cell. Biol. 10: 31253136.

Williams, G.T., T.K. McClanahan, and R.I. Morimoto. 1989. Ela transactivation of the human HSP70 promoter is mediated through the basal transcriptional complex. Mol. Cell. Biol. 9: 2574-2587.

Wu, B. and R.I. Morimoto. 1985. Transcription of the human hsp70 gene is induced by serum stimulation. Proc. Natl. Acad. Sci. 82: 6070-6074.

Wu, B., C. Hunt, and R.I. Morimoto. 1985. Structure and expression of the human gene encoding major heat shock protein HSP70. Mol. Cell. Biol. 5: 330-341.

$\mathrm{Wu}, \mathrm{B} ., \mathrm{R}$. Kingston, and R.I. Morimoto. 1986. Human hsp70 promoter contains at least two distinct regulatory domains. Proc. Natl. Acad. Sci. 83: 629-633.

Wu, B., G.T. Williams, and R.I. Morimoto. 1987. Detection of three protein binding sites in the serum regulated promoter of the human gene encoding the $70-\mathrm{kDa}$ heat shock protein. Proc. Natl. Acad. Sci. 84: 2203-2207.

$\mathrm{Wu}, \mathrm{C} .1984$. Two protein-binding sites in chromatin implicated in the activation of heat shock genes. Nature 311: 8184.

Wu, C., S. Wilson, S. Walker, I. Dawid, T. Paisley, V. Zimarino, and H. Ueda. 1987. Purification and properties of Drosophila heat shock activator protein. Science 238: 1247-1253.

Xiao, H. and J.T. Lis. 1988. Germline transformation used to define key features of the heat shock response element. Science 239: 1139-1142.

Xiao, H., O. Perisic, and J.T. Lis.1991. Cooperative binding of Drosophila heat shock factor to arrays of a conserved 5-bp unit. Cell 64: 585-593. 


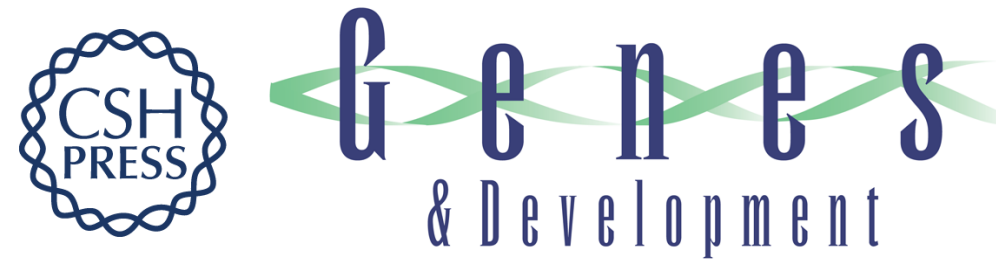

\section{Attenuation of the heat shock response in HeLa cells is mediated by the release of bound heat shock transcription factor and is modulated by changes in growth and in heat shock temperatures.}

K Abravaya, B Phillips and R I Morimoto

Genes Dev. 1991, 5:

Access the most recent version at doi:10.1101/gad.5.11.2117

References This article cites 41 articles, 27 of which can be accessed free at: http://genesdev.cshlp.org/content/5/11/2117.full.html\#ref-list-1

License

Email Alerting Service

Receive free email alerts when new articles cite this article - sign up in the box at the top right corner of the article or click here.

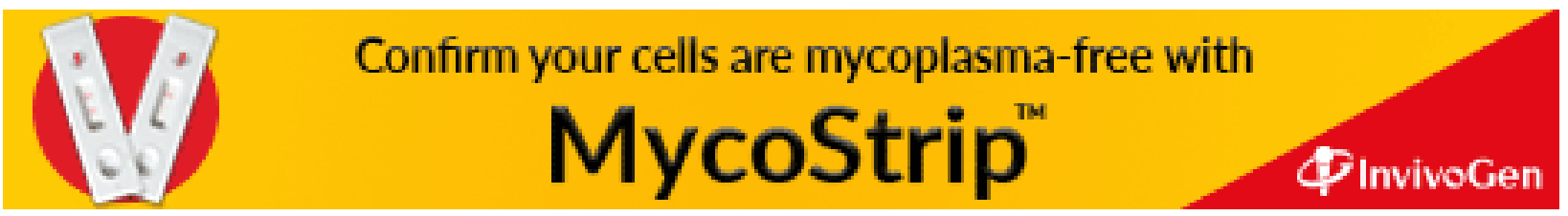

